\title{
Interface Study on Amorphous Indium Gallium Zinc Oxide Thin Film Transistors Using High-k Gate Dielectric Materials
}

\author{
Yu-Hsien Lin and Jay-Chi Chou \\ Department of Electronic Engineering, National United University, No. 1 Lienda, Miaoli 36003, Taiwan \\ Correspondence should be addressed to Yu-Hsien Lin; yhlin@nuu.edu.tw
}

Received 1 September 2015; Accepted 23 November 2015

Academic Editor: Christian Brosseau

Copyright ( 2015 Y.-H. Lin and J.-C. Chou. This is an open access article distributed under the Creative Commons Attribution License, which permits unrestricted use, distribution, and reproduction in any medium, provided the original work is properly cited.

\begin{abstract}
We investigated amorphous indium gallium zinc oxide (a-IGZO) thin film transistors (TFTs) using different high-k gate dielectric materials such as silicon nitride $\left(\mathrm{Si}_{3} \mathrm{~N}_{4}\right)$ and aluminum oxide $\left(\mathrm{Al}_{2} \mathrm{O}_{3}\right)$ at low temperature process $\left(<300^{\circ} \mathrm{C}\right)$ and compared them with low temperature silicon dioxide $\left(\mathrm{SiO}_{2}\right)$. The IGZO device with high-k gate dielectric material will expect to get high gate capacitance density to induce large amount of channel carrier and generate the higher drive current. In addition, for the integrating process of integrating IGZO device, postannealing treatment is an essential process for completing the process. The chemical reaction of the high-k/IGZO interface due to heat formation in high-k/IGZO materials results in reliability issue. We also used the voltage stress for testing the reliability for the device with different high-k gate dielectric materials and explained the interface effect by charge band diagram.
\end{abstract}

\section{Introduction}

The emergence of transparent thin film transistors (TTFTs) has enabled satisfying consumer requirements for electronic products. Because of their numerous advantages, TTFTs are anticipated to become the next generation of transistor materials. Among the various types of transparent thin film materials currently in use, indium gallium zinc oxide (IGZO) is extremely promising [1-6]. IGZO is highly flexible and has a carrier mobility of up to $10 \mathrm{~cm}^{2} \cdot \mathrm{V}^{-1} \cdot \mathrm{s}^{-1}[7]$. These properties have had a considerable impact on advancing the applications of TTFTs.

The energy gap of IGZO approximates $3.1 \mathrm{eV}$ [8]. The transmittance rate of IGZO can reach up to $90 \%$, exceeding $80 \%$ under certain annealing conditions [9]. The main structure of IGZO is $\mathrm{ZnO}$ doped with $\mathrm{In}^{3+}$ and $\mathrm{Ga}^{3+}$; trivalent indium and gallium can be used as replacements for divalent zinc to provide additional cations for enhancing carrier mobility. According to previous studies, doping IGZO with indium enhances its carrier mobility, whereas including gallium reduces its carrier mobility. Including indium provides extra cations; In-O has a weak bond that can be broken easily to produce oxygen vacancies. Although including gallium reduces carrier mobility, it does not have a marked effect on distorting the original lattice because the bond length of $\mathrm{Ga}-$ $\mathrm{O}$ approximates to that of $\mathrm{Zn}-\mathrm{O}$ and $\mathrm{Zn}^{2+}$ and $\mathrm{Ga}^{3+}$ have a nearly identical radius. The bonding of $\mathrm{Ga}-\mathrm{O}$ is far stronger than those of In-O and $\mathrm{Zn}-\mathrm{O}$; thus, oxygen vacancies can be inhibited by utilizing the $\mathrm{Ga}-\mathrm{O}$ bond. Because of these properties, fabricating IGZO thin films does not introduce excessive defects and cause deterioration in their electrical property. The doping ratio of indium, gallium, and zinc can influence the crystal structure and carrier mobility. Currently, IGZO doped with indium : gallium : zinc : oxygen at a ratio of $1: 1: 1: 4$ has been used in many studies [10-13].

Nowadays, many semiconductor manufacture companies are currently using the high-k dielectric materials as replacement materials for $\mathrm{SiO}_{2}$ as the gate dielectric materials for complementary metal-oxide-semiconductor (CMOS) process [14-16]. The required properties of gate dielectrics need considering the key guidelines such as high dielectric constant, proper conduction and valence-band offset, thermodynamic stability, interface quality, process compatibility, and device reliability. With high-k gate dielectric materials, the high drive currents with large capacitance, low leakage current, and low operation voltage could be achieved for CMOS devices. 


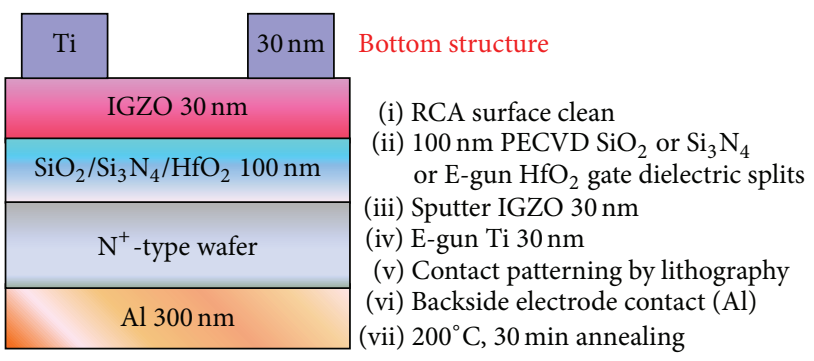

FIGURE 1: Cross section of the fabricated bottom-gate a-IGZO TFTs using high-k materials.

In this paper, we integrate the a-IGZO thin film transistors by using different high-k gate dielectric materials and research the interface between the high- $\mathrm{k}$ dielectric thin film/IGZO interfaces through the thermal annealing. We use the low temperature PECVD $\mathrm{SiO}_{2}, \operatorname{PECVD~} \mathrm{Si}_{3} \mathrm{~N}_{4}$, and room temperature E-gun $\mathrm{Al}_{2} \mathrm{O}_{3}$ thin film for the gate dielectric material. The effect of temperature treatment on a-IGZO TFTs was studied due to the interface reaction. The thermal budget is crucial and will influence the device characteristics such as subthreshold swing (SS), $I_{\mathrm{ON}} / I_{\mathrm{OFF}}$ ratio, carrier mobility, and stress characteristics. Moreover, the stress effect of the IGZO device was explained by using energy band diagram for the electrical characteristics of aIGZO TFTs.

\section{Fabrication}

The a-IGZO TFTs with different high-k dielectric were fabricated by using $\mathrm{N}^{+}$-type wafers and a bottom gate structure, as shown in Figure 1. By using the bottom structure, we could focus on the interface between the high-k dielectric thin film/IGZO interfaces through thermal annealing [17, 18]. First, after the RCA clean, three different gate dielectric materials were deposited with thickness of $10 \mathrm{~nm}$. The splits were $\mathrm{SiO}_{2}$ by using PECVD method at $300^{\circ} \mathrm{C}, \mathrm{Si}_{3} \mathrm{~N}_{4}$ by using PECVD method at $300^{\circ} \mathrm{C}$, and $\mathrm{Al}_{2} \mathrm{O}_{3}$ by using E-gun method at room temperature, respectively. For comparison with above layers, we also use furnace $\mathrm{SiO}_{2}$ at $950^{\circ} \mathrm{C}$ as optimized gate oxide to eliminate the interface effect. Then, a $30 \mathrm{~nm}$ a-IGZO layer was deposited using sputtering method with $\mathrm{IGZO}_{4}$ targets (In: $\mathrm{Ga}: \mathrm{Zn}: \mathrm{O}$ ratio of $1: 1: 1: 4$ ) in ambient oxygen gas $\left(\mathrm{O}_{2}\right)$. The cosputtering process was performed at $4 \times 10^{-3}$ Torr in room temperature with precursors of $\mathrm{O}_{2}$ $(6 \mathrm{sccm})$ and $\operatorname{Ar}(24 \mathrm{sccm})$, and the DC sputter power was set at $150 \mathrm{~W}$. After active region patterning, $30 \mathrm{~nm}$ titanium (Ti) thin film was deposited and used for source and drain electrodes, using the E-gun method at room temperature. After source/drain patterning, postannealing treatment was performed for 30 minutes at temperature of $200^{\circ} \mathrm{C}$. The dimensions of the devices were length/width dimensions of $200 / 1000 \mu \mathrm{m}$.

\section{Results and Discussion}

The basic $I_{d}-V_{g}$ curve of the a-IGZO TFTs using high-k materials is shown in Figure 2(a). For the measurement, the
TABLE 1: The summary table for the a-IGZO TFTs using high-k materials.

\begin{tabular}{lcccc}
\hline & $V_{t}(\mathrm{~V})$ & S.S (V/dec. $)$ & $\mu\left(\mathrm{cm}^{2} / \mathrm{V}\right.$-s $)$ & $I_{\mathrm{ON}} / I_{\mathrm{OFF}}$ \\
\hline $\mathrm{PECVD} \mathrm{SiO}_{2}$ & 0.09 & 0.100 & 3.50 & $2.1 \times 10^{-5}$ \\
PECVD Si $_{3} \mathrm{~N}_{4}$ & 0.20 & 0.151 & 8.96 & $8.5 \times 10^{-6}$ \\
${\text { E-gun } \mathrm{Al}_{2} \mathrm{O}_{3}}$ & -0.03 & 0.270 & 8.07 & $8.4 \times 10^{-6}$ \\
\hline
\end{tabular}

gate voltage varied from -5 to $5 \mathrm{~V}$ and the drain voltage was $1 \mathrm{~V}$. Figure 2(b) shows the $I_{d}-V_{d}$ curve of the a-IGZO TFTs, and the drain voltage varied from 0 to $10 \mathrm{~V}$ and the gate voltages were $0,2.5$, and $5 \mathrm{~V}$. We could observe that the $\mathrm{Si}_{3} \mathrm{~N}_{4}$ sample has higher $I_{\mathrm{ON}}$, lower $I_{\mathrm{OFF}}$, higher $I_{\mathrm{ON}} / I_{\mathrm{OFF}}$ ratio, and high mobility due to the higher dielectric constant compared to $\mathrm{SiO}_{2}$ sample and $\mathrm{Al}_{2} \mathrm{O}_{3}$ sample. However, the $\mathrm{SiO}_{2}$ sample has good SS compared to others because of good interface with IGZO. The a-IGZO TFTs with $\mathrm{Si}_{3} \mathrm{~N}_{4}$ gate dielectric exhibited superior characteristics. The summary table of the measurement data is shown in Table 1.

As shown in Figures 3(a)-3(d), following a gate voltage stress of $-5 \mathrm{~V}, V_{t}$ of PECVD $\mathrm{SiO}_{2}$ and E-gun $\mathrm{Al}_{2} \mathrm{O}_{3}$ sample increased as the stress time lengthened, and $V_{t}$ slightly shifted to the right; by contrast, for the PECVD $\mathrm{Si}_{3} \mathrm{~N}_{4}$ sample, $V_{t}$ shifted to the left. Following a gate voltage stress of $+5 \mathrm{~V}$, PECVD $\mathrm{SiO}_{2}$ and E-gun $\mathrm{Al}_{2} \mathrm{O}_{3}$ sample have deterioration just like device on, and the E-gun $\mathrm{Al}_{2} \mathrm{O}_{3}$ sample deteriorated more apparently than did the PECVD $\mathrm{SiO}_{2}$ sample. By contrast, for the PECVD $\mathrm{Si}_{3} \mathrm{~N}_{4}$ sample, $V_{t}$ shifted to the right as the stress time increased and did not deteriorate. To determine the problem causing the observed phenomena, $\mathrm{SiO}_{2}$ gateinsulating layer with the same thickness was developed using a horizontal furnace tube through the dry oxide method at $950^{\circ} \mathrm{C}$, as shown in Figure 3(d). The dry oxide formed using horizontal furnace was used as the control sample. The results showed that, following numerous sweeps of negative gate voltage stress, the components exhibited minimal change in characteristics. Following the positive voltage stress tests, $V_{t}$ neither shifted to the left nor deteriorated. These results accord with the trend observed for $\mathrm{Si}_{3} \mathrm{~N}_{4}$ sample and the characteristics of positive gate voltage stress [19-21]. This phenomenon is attributed to the interface effect between the gate-insulating layer and the IGZO. Thus, the problem was related to changes in the interface after stressing. Moreover, we could also calculate the interface trap density $\left(D_{\mathrm{it}}\right)$ by the difference of the subthreshold swing (SS) between the original sample and stressed sample. The interface trap density $\left(D_{\text {it }}\right)$ was calculated based on the equation $S S=k T / q \times \ln 10 \times$ $\left(1+\left(C_{b}+C_{\mathrm{it}}\right) / C_{\mathrm{HK}}\right)$, where $C_{b}$ is the depletion capacitance density of IGZO and $C_{\text {it }}\left(=q D_{\text {it }}\right)$ is the capacitance density from charged interface traps $[22,23]$. By neglecting $C_{b}, D_{\text {it }}$ for the original PECVD $\mathrm{SiO}_{2}$ sample, PECVD $\mathrm{Si}_{3} \mathrm{~N}_{4}$ sample, and E-gun $\mathrm{Al}_{2} \mathrm{O}_{3}$ sample are $2.9 \times 10^{12}, 6.6 \times 10^{12}$, and $5.3 \times 10^{12} \mathrm{~cm}^{-2} \mathrm{eV}^{-1}$, respectively. After voltage positive gate voltage stress for 10 seconds, $D_{\mathrm{it}}$ for the stressed PECVD $\mathrm{SiO}_{2}$ sample, PECVD $\mathrm{Si}_{3} \mathrm{~N}_{4}$ sample, and E-gun $\mathrm{Al}_{2} \mathrm{O}_{3}$ sample are $3.5 \times 10^{12}, 6.9 \times 10^{12}$, and $7.1 \times 10^{12} \mathrm{~cm}^{-2} \mathrm{eV}^{-1}$, respectively. For the comparison with the original and the stressed device, the degradation ratios of the PECVD $\mathrm{SiO}_{2}$ sample, PECVD 


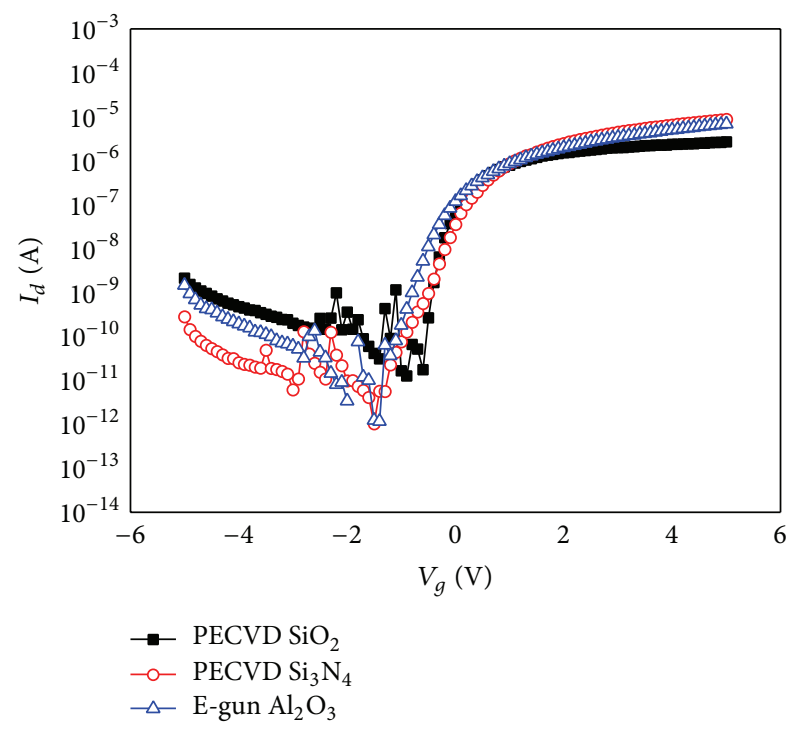

(a)

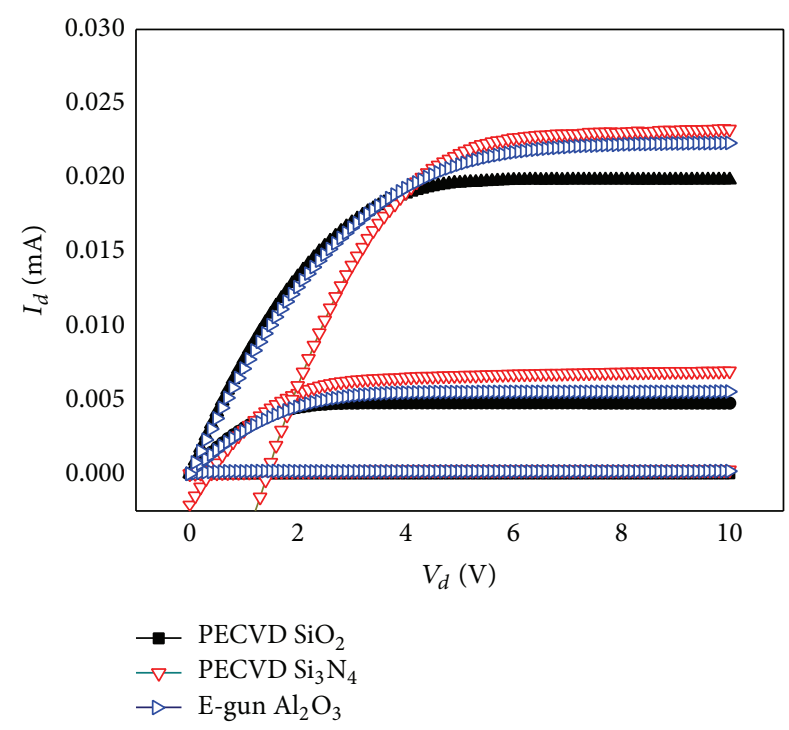

(b)

FIGURE 2: (a) $I_{d}-V_{g}$ curve of the a-IGZO TFTs using high-k materials. (b) $I_{d}-V_{d}$ curve of the a-IGZO TFTs using high-k materials.

$\mathrm{Si}_{3} \mathrm{~N}_{4}$ sample, and E-gun $\mathrm{Al}_{2} \mathrm{O}_{3}$ sample are $20.6 \%, 4.5 \%$, and $34.0 \%$, respectively. As a result, the IGZO TFTs with $\mathrm{Si}_{3} \mathrm{~N}_{4}$ gate dielectric have the lowest $D_{\text {it }}$ after stressing.

According to the experimental results, the type of gate oxide layer had a substantial influence on the performance of the IGZO thin film transistor (TFT). As indicated in previous studies, stress-induced component characteristics are analogous to those of PECVD $\mathrm{Si}_{3} \mathrm{~N}_{4}$ sample and dry oxide sample (control), demonstrating shifts in their $V_{t}$. Such shift is attributed to the donor-like trap at the interface between the insulating layer and IGZO layer. As shown in Figure 4, generally, a donor-like carrier located below the Fermi level is considered as a neutral carrier, whereas one located above the Fermi level is considered as a positively charged carrier. When positive voltage stress is applied to a gate, the conduction band bends downward because of the electric field, reducing the distance between the contact surface and the Fermi level. This behavior suggests that the number of positively charged donor-like carriers between the conduction band and Fermi level decreases, increasing the number of neutral carriers. If the conduction band that bends because of stress is measured before it returns to its unbent state, then $V_{t}$ becomes large and shifts to the right because of the decrease in the number of positive charges; consequently, the conduction band cannot attract more electrons and higher voltage is required to obtain the same number of electrons. Conversely, when negative voltage stress is applied to a gate, the conduction band bends upward, the number of positively charged donor-like carriers increases, and the number of neutral carriers decreases, thus diminishing $V_{t}$ and shifting $V_{t}$ to the left [21].

In low temperature processes, except for PECVD $\mathrm{Si}_{3} \mathrm{~N}_{4}$ sample in the gate-insulating layer, the channels of other insulting layer materials cannot close under positive voltage stress. Disregarding the fact that this phenomenon is a result of $I_{g}$ current induced by the collapse of the insulating layer, this study considered interface-related problems. Some IGZO
TABLE 2: Gate-insulating layer and heat formation in IGZO compounds.

\begin{tabular}{lcccccc}
\hline & \multicolumn{3}{c}{ Gate-insulating layer } & \multicolumn{3}{c}{ IGZO } \\
\hline Heat of formation $\mathrm{Si}_{3} \mathrm{~N}_{4}$ & $\mathrm{SiO}_{2}$ & $\mathrm{Al}_{2} \mathrm{O}_{3}$ & $\mathrm{In}_{2} \mathrm{O}_{3}$ & $\mathrm{Ga}_{2} \mathrm{O}_{3}$ & $\mathrm{ZnO}$ \\
$\Delta H_{f}{ }^{\circ}(\mathrm{kJ} / \mathrm{mol})$ & -743.5 & -910.7 & -1675.7 & -925 & -1089.1 & -350.5 \\
\hline
\end{tabular}

carriers are provided by oxygen vacancies; therefore, in this study, the responses of the interface between the IGZO and insulating layer materials were examined to determine whether the IGZO and the insulating layer materials competed for oxygen and whether the IGZO produces extra oxygen vacancies. The standard heat of formation $\Delta H_{f}{ }^{\circ}$ indicates that $\mathrm{Al}_{2} \mathrm{O}_{3}<\mathrm{SiO}_{2}<\mathrm{Si}_{3} \mathrm{~N}_{4}[24,25]$. As shown in Table 2, the forming of negative heat indicates that a chemical compound is stable, the probability of interface formation is large, and the chemical compounds in IGZO compete for oxygen (according to the table, the heat formation in $\mathrm{ZnO}$ is close to zero; thus, the oxygen in $\mathrm{ZnO}$ is most likely occupied). The behaviors of the $\mathrm{SiO}_{2}$ control sample formed through using a horizontal furnace tube and $\mathrm{SiO}_{2}$ sample developed through plasma-enhanced chemical vapor deposition have resulted from oxide layer defects near the interface.

According to the aforementioned hypothesis, the following explanations for deterioration were proposed. When a gate is influenced by positive voltage stress, accumulated IGZO electrons may be trapped in the interface or in the oxide layer defects. These trapped electrons generate electric fields even when voltage stress is not applied. Accordingly, the conduction band can bend downward without positive voltage stress causing electrons to accumulate. If the insulating layer accepts oxygen in the IGZO, then additional oxygen vacancies and electrons are produced. Once additional electrons under positive voltage stress are trapped in the interface 


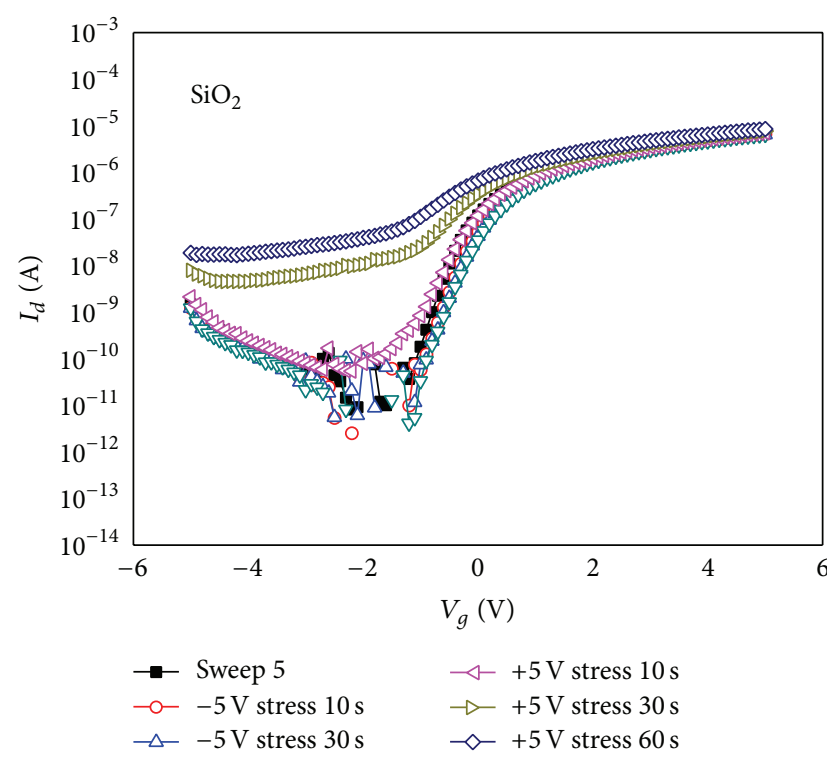

(a)

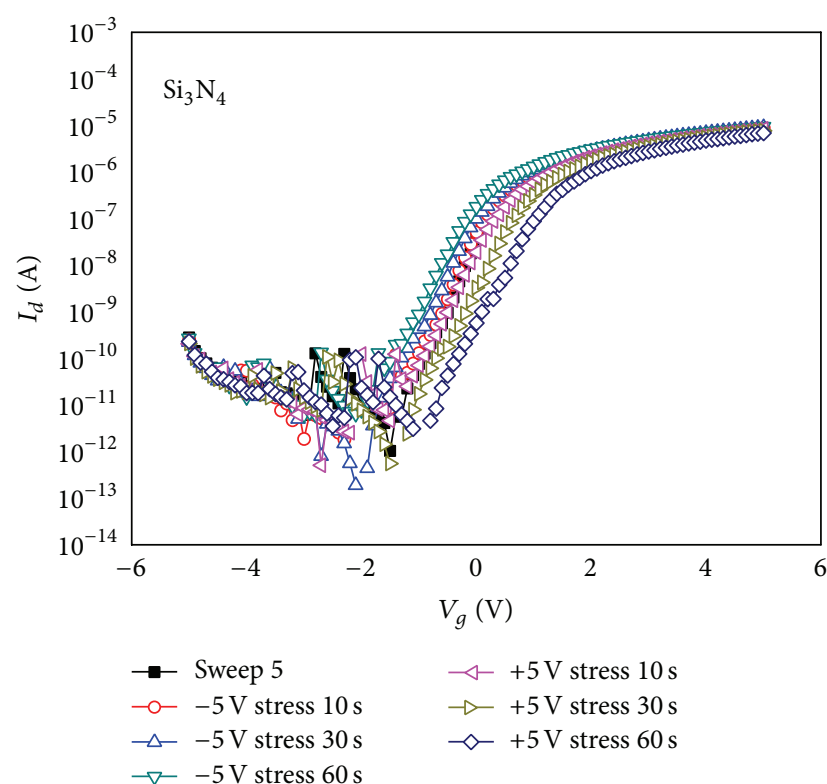

(c)

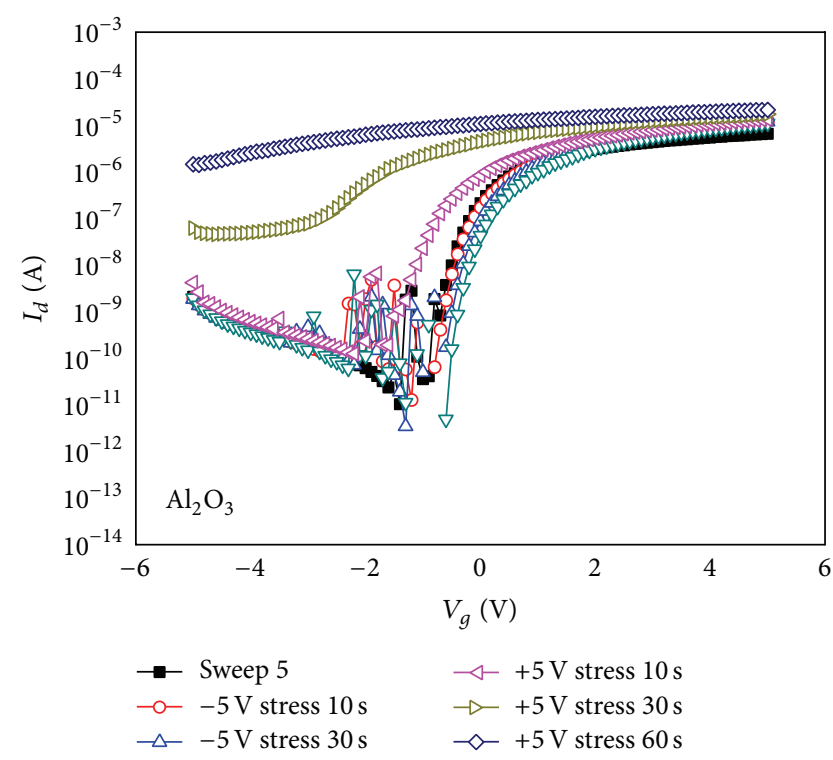

(b)

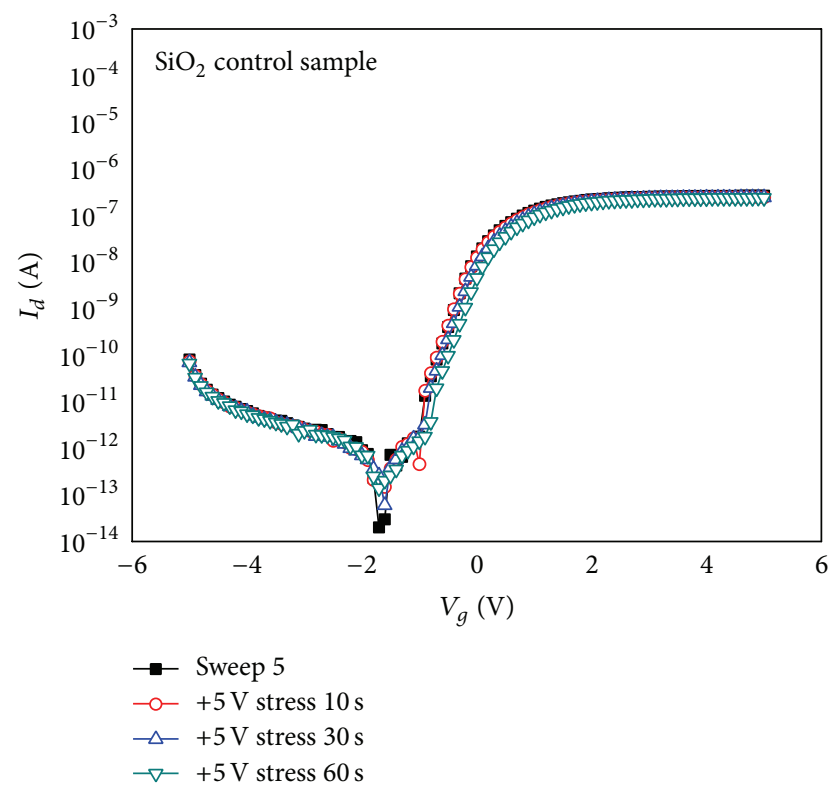

(d)

Figure 3: Various insulating layers with $\pm 5 \mathrm{~V}$ stress for $I_{d}-V_{g}$ comparison: (a) $\mathrm{PECVD} \mathrm{SiO}_{2}$, (b) E-gun $\mathrm{Al}_{2} \mathrm{O}_{3}$, (c) $\mathrm{PECVD} \mathrm{Si}_{3} \mathrm{~N}_{4}$, and (d) $\mathrm{SiO}_{2}$ control sample of furnace process.

or in the oxide layer defects, the conduction band is severely bent downward and a considerable number of electrons accumulate. Consequently, the component channels cannot close and the band diagram was shown in Figure 5.

\section{Conclusion}

In this paper, we demonstrate the low temperature IGZO TFT device with different high-k gate dielectric materials such as $\mathrm{PECVD} \mathrm{Si}_{3} \mathrm{~N}_{4}\left(300^{\circ} \mathrm{C}\right.$ ) and E-gun $\mathrm{Al}_{2} \mathrm{O}_{3}$ (room temperature) and they are compared to the $\mathrm{PECVD} \mathrm{SiO}_{4}$ $\left(300^{\circ} \mathrm{C}\right)$. The PECVD $\mathrm{Si}_{3} \mathrm{~N}_{4}$ sample could yield high mobility, high $I_{\mathrm{ON}} / I_{\mathrm{OFF}}$ ratio, high $I_{\mathrm{ON}}$, low $I_{\mathrm{OFF}}$, and better stress effect than others. The stability between the high-k dielectric thin film and IGZO thin film caused interface roughness due to the heat formation difference during temperature annealing. The charge is generated in the interface and results in $V_{t}$ shift during stress. The stress effect could be explained in the interface by charge band diagram. As a result, the IGZO TFTs with $\mathrm{Si}_{3} \mathrm{~N}_{4}$ gate dielectric exhibit good characteristics with acceptable reliability in the low temperature process. 


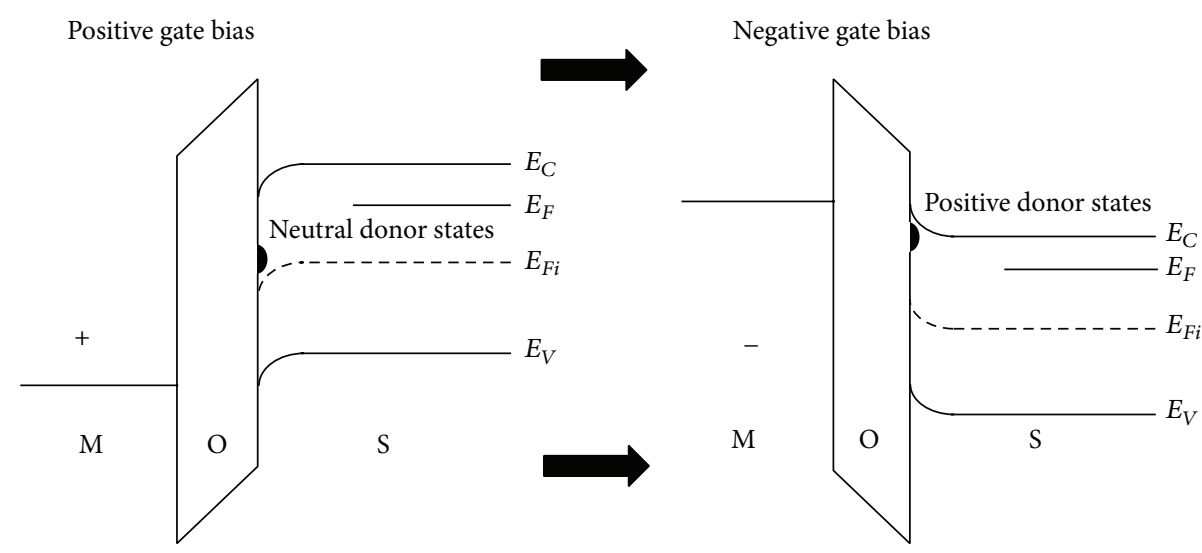

FIGURE 4: Mechanisms of positive and negative gate voltage stress.

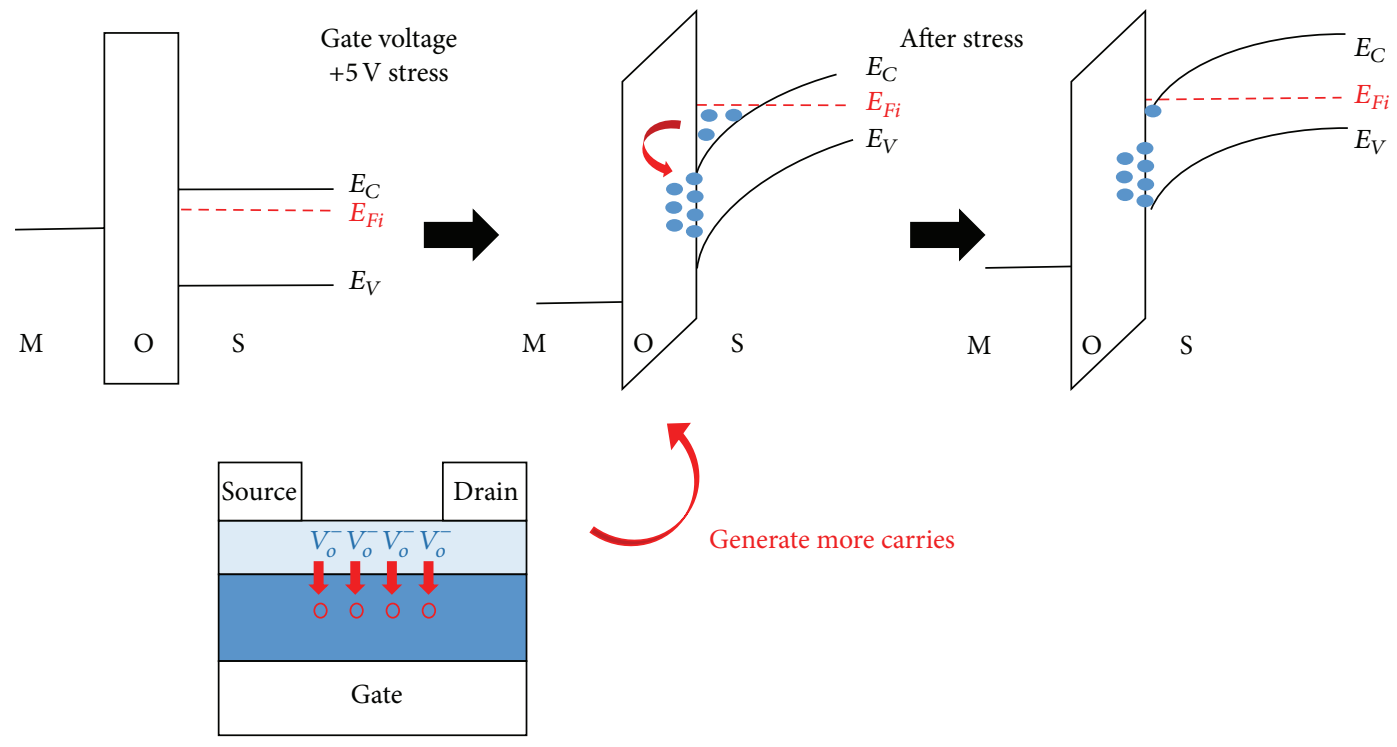

FIGURE 5: Deterioration of components after applying positive gate voltage stress.

\section{Conflict of Interests}

The authors declare that there is no conflict of interests regarding the publication of this paper.

\section{Acknowledgments}

This study was sponsored by the Ministry of Science and Technology, Taiwan, under Contract no. 104-2221-E-239017. The technical support of the National Nano Device Laboratories is also greatly appreciated.

\section{References}

[1] T. Kamiya, K. Nomura, and H. Hosono, "Origins of high mobility and low operation voltage of amorphous oxide TFTs: electronic structure, electron transport, defects and doping," Journal of Display Technology, vol. 5, no. 7, pp. 273-288, 2009.

[2] C.-L. Fan, M.-C. Shang, B.-J. Li et al., "A self-aligned a-IGZO thin-film transistor using a new two-photo-mask process with a continuous etching scheme," Materials, vol. 7, no. 8, pp. 5761$5768,2014$.

[3] A. Takagi, K. Nomura, H. Ohta et al., "Carrier transport and electronic structure in amorphous oxide semiconductor, aInGaZnO ${ }_{4}$," Thin Solid Films, vol. 486, no. 1-2, pp. 38-41, 2005.

[4] C. J. Chiu, Z. W. Pei, S. P. Chang, and S. J. Chang, "Influence of weight ratio of poly(4-vinylphenol) insulator on electronic properties of InGaZnO thin-film transistor," Journal of Nanomaterials, vol. 2012, Article ID 698123, 7 pages, 2012.

[5] C.-M. Hsu, W.-C. Tzou, C.-F. Yang, and Y.-J. Liou, "Investigation of the high mobility IGZO thin films by using co-sputtering method," Materials, vol. 8, no. 5, pp. 2769-2781, 2015.

[6] C.-L. Fan, M.-C. Shang, B.-J. Li et al., "Teflon $/ \mathrm{SiO}_{2}$ bilayer passivation for improving the electrical reliability of oxide TFTs fabricated using a new two-photomask self-alignment process," Materials, vol. 8, no. 4, pp. 1704-1713, 2015.

[7] K. Nomura, H. Ohta, A. Takagi, T. Kamiya, M. Hirano, and H. Hosono, "Room-temperature fabrication of transparent flexible thin-film transistors using amorphous oxide semiconductors," Nature, vol. 432, no. 7016, pp. 488-492, 2004. 
[8] K. Nomura, T. Kamiya, H. Yanagi et al., "Subgap states in transparent amorphous oxide semiconductor, In-Ga-Zn-O, observed by bulk sensitive x-ray photoelectron spectroscopy," Applied Physics Letters, vol. 92, no. 20, Article ID 202117, 2008.

[9] Y. Wang, S. W. Liu, X. W. Sun et al., "Highly transparent solution processed In-Ga-Zn oxide thin films and thin film transistors," Journal of Sol-Gel Science and Technology, vol. 55, no. 3, pp. 322327, 2010.

[10] H. Kumomi, K. Nomura, T. Kamiya, and H. Hosono, "Amorphous oxide channel TFTs," Thin Solid Films, vol. 516, no. 7, pp. 1516-1522, 2008.

[11] K. Nomura, A. Takagi, T. Kamiya, H. Ohta, M. Hirano, and H. Hosono, "Amorphous oxide semiconductors for highperformance flexible thin-film transistors," Japanese Journal of Applied Physics, vol. 45, no. 5, pp. 4303-4308, 2006.

[12] H. Hosono, "Ionic amorphous oxide semiconductors: material design, carrier transport, and device application," Journal of Non-Crystalline Solids, vol. 352, no. 9-20, pp. 851-858, 2006.

[13] T. Iwasaki, N. Itagaki, T. Den et al., "Combinatorial approach to thin-film transistors using multicomponent semiconductor channels: an application to amorphous oxide semiconductors in In-Ga-Zn-O system," Applied Physics Letters, vol. 90, no. 24, Article ID 242114, 2007.

[14] Y. Kamata, "High-k/Ge MOSFETs for future nanoelectronics," Materials Today, vol. 11, no. 1-2, pp. 30-38, 2008.

[15] M. M. Frank, S.-B. Kim, S. L. Brown et al., "Scaling the MOSFET gate dielectric: from high- $k$ to higher- $k$," Microelectronic Engineering, vol. 86, no. 7-9, pp. 1603-1608, 2009.

[16] M. Suzuki, "Comprehensive study of lanthanum aluminate high-dielectric-constant gate oxides for advanced CMOS devices," Materials, vol. 5, no. 3, pp. 443-477, 2012.

[17] T. B. Singh, N. S. Sariciftci, and J. G. Grote, "Bio-organic optoelectronic devices using DNA," in Organic Electronics, vol. 223 of Advances in Polymer Science, pp. 73-112, Springer, Berlin, Germany, 2010.

[18] L. Ge, L. Ming, W. Hong et al., "Study of top and bottom contact resistance in one organic field-effect transistor," Chinese Physics $B$, vol. 18, no. 8, pp. 3530-3534, 2009.

[19] W.-T. Chen, S.-Y. Lo, S.-C. Kao et al., "Oxygen-dependent instability and annealing/passivation effects in amorphous InGa-Zn-O thin-film transistors," IEEE Electron Device Letters, vol. 32, no. 11, pp. 1552-1554, 2011.

[20] E. N. Cho, J. H. Kang, C. E. Kim, P. Moon, and I. Yun, "Analysis of bias stress instability in amorphous InGaZnO thinfilm transistors," IEEE Transactions on Device and Materials Reliability, vol. 11, no. 1, pp. 112-117, 2011.

[21] Y.-M. Kim, K.-S. Jeong, H.-J. Yun et al., "Anomalous stressinduced hump effects in amorphous indium gallium zinc oxide TFTs," Transactions on Electrical and Electronic Materials, vol. 13, no. 1, pp. 47-49, 2012.

[22] H.-H. Hsu, C.-Y. Chang, and C.-H. Cheng, "Room-temperature flexible thin film transistor with high mobility," Current Applied Physics, vol. 13, no. 7, pp. 1459-1462, 2013.

[23] H. H. Hsu, C. Y. Chang, and C. H. Cheng, "High performance IGZO/TiO 2 thin film transistors using $\mathrm{Y}_{2} \mathrm{O}_{3}$ buffer layers on polycarbonate substrate," Applied Physics A: Materials Science and Processing, vol. 112, no. 4, pp. 817-820, 2013.

[24] Y.-H. Lin and J.-C. Chou, "Temperature effects on a-IGZO thin film transistors using $\mathrm{HfO}_{2}$ gate dielectric material," Journal of Nanomaterials, vol. 2014, Article ID 347858, 5 pages, 2014.

[25] http://www.update.uu.se/ jolkkonen/pdf/CRC_TD.pdf. 

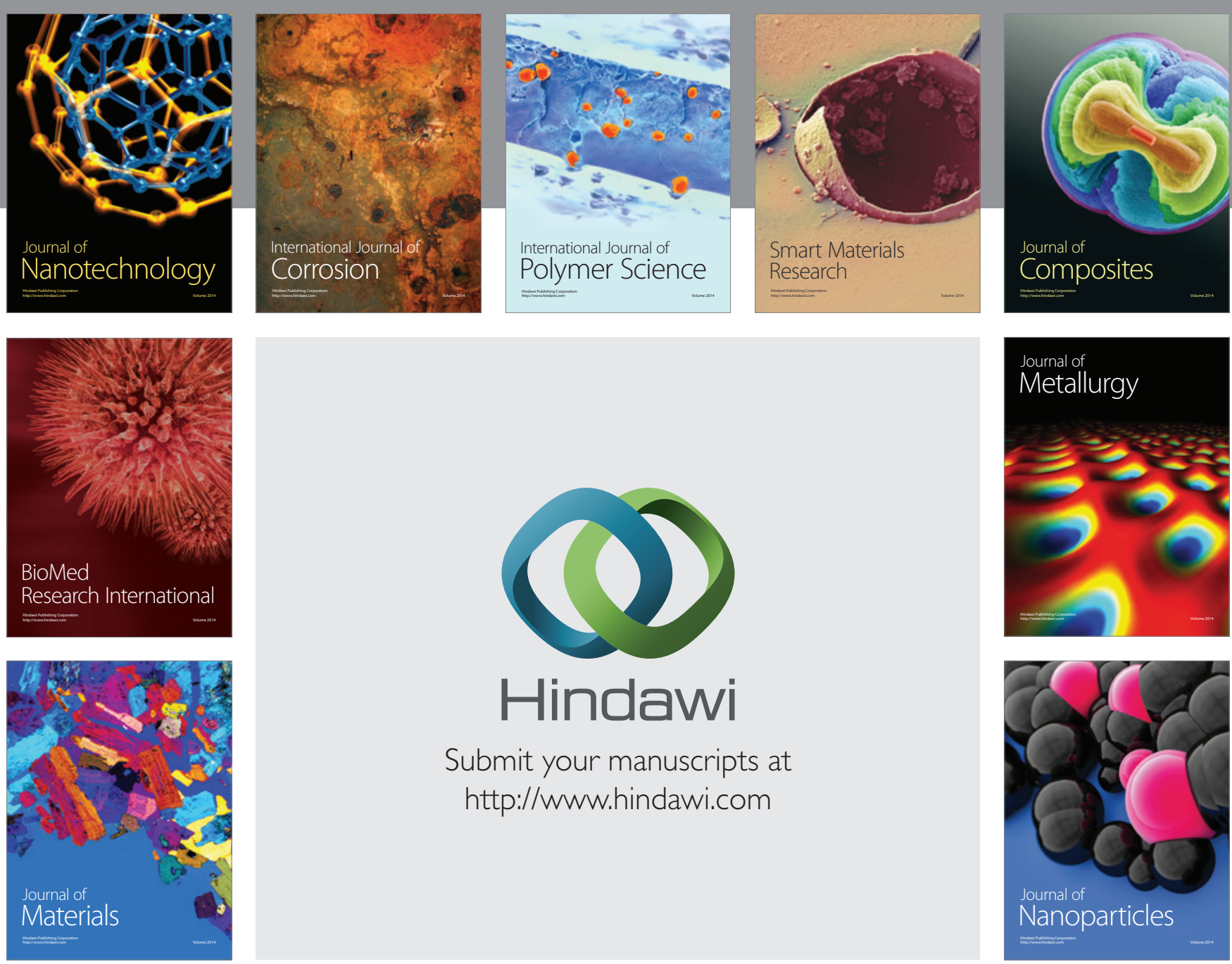

Submit your manuscripts at http://www.hindawi.com
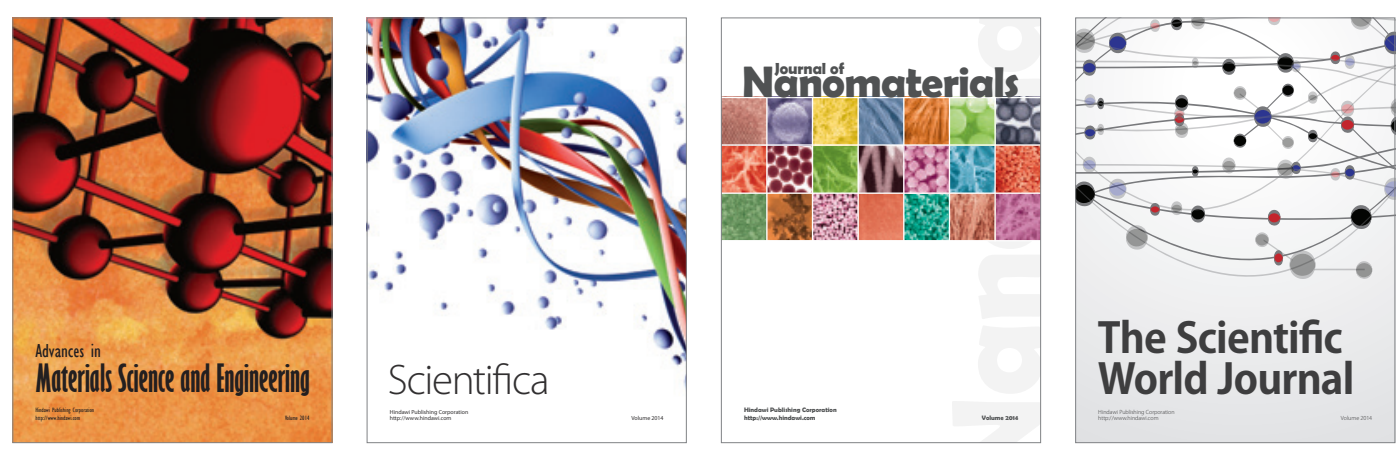

\section{The Scientific World Journal}
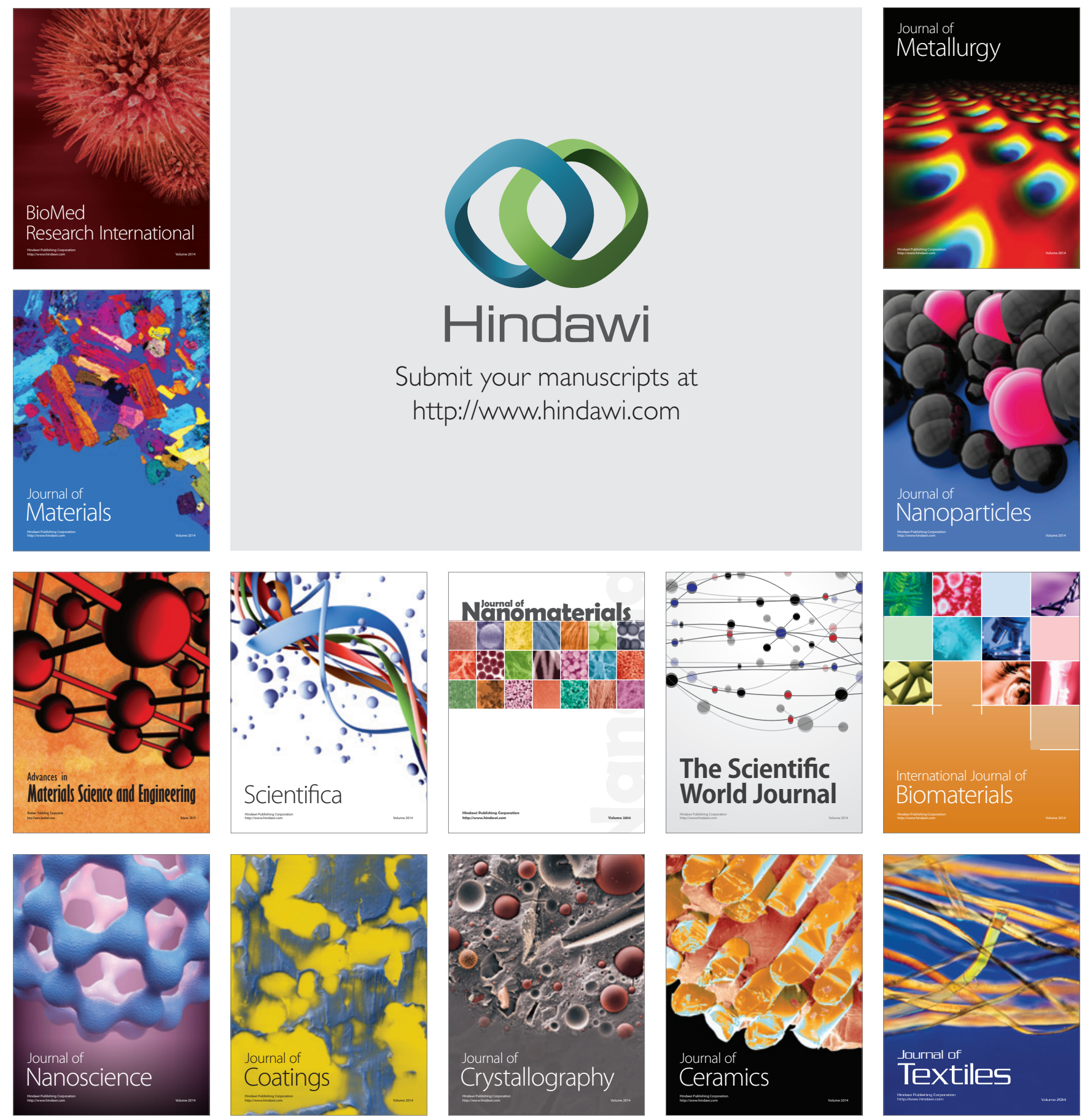